\title{
Properties of Siloxane Based Optical Waveguides Deposited on Transparent Paper and Foil
}

\author{
Vaclav PRAJZLER ${ }^{1}$, Petr HYPS ${ }^{1}$, Radek MASTERA ${ }^{1}$, Pavla NEKVINDOVA ${ }^{2}$ \\ ${ }^{1}$ Dept. of Microelectronics, Czech Technical University, Technická 2, 16827 Prague, Czech Republic \\ ${ }^{2}$ Institute of Chemical Technology, Technická 5, 16627 Prague, Czech Republic
}

xprajzlv@feld.cvut.cz

Manuscript received February 02, 2016

\begin{abstract}
In this paper, we present the properties of flexible planar optical waveguides made of siloxane-based polymer deposited on Xerox transparent paper and PLEXIGLAS foil substrate. Measurement of optical properties such as the waveguiding properties and refractive index is carried out by the prism coupling technique for five wavelengths (473, 632.8, 964, 1311 and $1552 \mathrm{~nm}$ ) and propagation optical loss were measured by the fiber probe technique at a wavelength of $632.8 \mathrm{~nm}$ (He-Ne laser). The measurement proved waveguiding properties for all measured wavelengths and the losses generally did not exceed $0.40 \mathrm{~dB} \cdot \mathrm{cm}^{-1}$; the best samples had optical losses around $0.24 \mathrm{~dB} \cdot \mathrm{cm}^{-1}$.
\end{abstract}

\section{Keywords}

Optical planar waveguides, siloxane polymer, flexible foil, prism coupling technique

\section{Introduction}

Next-generation internet switches and high-end computers are expected to process aggregate data rates in the order of Tbit/s. In consequence, the interconnections between the processing units will have to handle data rates in the order up to $40 \mathrm{Gbit} / \mathrm{s}$. It is, however, well known from basic physical laws that at such data rates, electrical interconnections will suffer from high transmission losses and severe signal integrity problems [1], [2]. Demand for continuous increase in transmission speed and data capacity drives innovations in the areas of broadband communications not only for long distance communications but nowadays also in transmission for short reach and extra short reach communications. Although silica optical fibers are used for high-speed data transfer over long distance, existing interconnection technologies for shorter distance used mainly metal copper wiring connection. Rising data-rates and their sensitivity to electromagnetic interference will not soon be sufficient due to the metallic wiring disadvantages. Therefore light as a transmission medium for the future interconnections is highly desirable as it has many advantages such as higher bandwidth, immunity from cross- talk and electromagnetic interference, easy fabrication process, low cost and etc. [3], [4].

Conventional optical links for optical interconnections are mainly realized on the base of semiconductors. Due to easy integration process with other optical and electrical elements, it is convenient to deposit the optical waveguides on silicon substrate [5], [6]. But silicon is not generally suitable for making any flexible and bendy optical interconnections. Therefore, new material-technology combinations for such utilization are highly needed to be searched for, esp. what concerns interconnections between rack-torack, board-to-board, multi-chip modules, and etc. For these types of data transfer it is necessary to connect optical circuits realized onto FR-4 glass epoxy substrates. For that purpose multimode optical fibers for optical devices interconnections have been already used, however new opportunities in the form of planar optical polymer waveguides are nowadays very tempting solution as well. Such new optical waveguides could be deposited onto transparent paper or foils and may have unique properties such us high transparency, low optical loss, suitable temperature stability and excellent flexibility/bendability.

Also polymer materials for fabrication of flexible planar optical waveguides appeared to be a good choice for their excellent optical properties such as their high transparency from visible to infra-red wavelengths, well-controlled refractive indices, reasonable temporal and temperature stability, low optical losses, easy fabrication process and low costs [7-13]. Substrates play a key role for photonics devices, therefore integration of optical waveguides and opto-electronic components onto transparent paper and flexible foils introduces a new concept of optical interconnection and flexibility into the on-board optical communications [14], [15]. Also over the past few years the demand for flexible substrates and the applications in which these flexible printed circuit boards are being used has been constantly growing [16].

Due to increasing demand for polymers not only for optical interconnection applications but also for other types of photonics structures, unique optical polymers have been recently developed. Unfortunately, only few materials from a large selection of commercially available optical polymers exhibit all of the required characteristics. The list 


\begin{tabular}{|c|c|c|c|}
\hline Polymer type & Manufacturer & $\alpha$ & $n$ \\
\hline $\begin{array}{l}\text { Cyclic olefin } \\
\text { copolymer }\end{array}$ & $\begin{array}{l}\text { Topas Advanced } \\
\text { Polymers company }\end{array}$ & $\begin{array}{c}0.5 \mathrm{~dB} / \mathrm{cm} \\
@ 830 \mathrm{~nm} \\
0.7 \mathrm{~dB} / \mathrm{cm} \\
@ 1550 \mathrm{~nm}\end{array}$ & 1.53 \\
\hline Cyclotone $^{\mathrm{TM}}$ & DOW Chemical & $\begin{array}{l}0.81 \mathrm{~dB} / \mathrm{cm} \\
\text { (a) } 1300 \mathrm{~nm}\end{array}$ & $\begin{array}{c}1.552 \\
@ 633 \mathrm{~nm} \\
1.537 \\
@ 1310 \mathrm{~nm} \\
1.535 \\
@ 1550 \mathrm{~nm} \\
\end{array}$ \\
\hline $\begin{array}{l}\text { Deuterated } \\
\text { polymethylmeth } \\
\text { acrylate }\end{array}$ & NTT & $\begin{array}{c}0.02 \mathrm{~dB} / \mathrm{cm} \\
@ 850 \mathrm{~nm} \\
0.07 \mathrm{~dB} / \mathrm{cm} \\
@ 1310 \mathrm{~nm}\end{array}$ & $\begin{array}{c}1.4886 \\
@ 830 \mathrm{~nm}\end{array}$ \\
\hline EpoCore & $\begin{array}{l}\text { micro resist } \\
\text { technology } \mathrm{GmbH}\end{array}$ & $\begin{array}{c}\sim 0.2 \mathrm{~dB} / \mathrm{cm} \\
\text { (a) } 850 \mathrm{~nm}\end{array}$ & $\begin{array}{c}1.580 \\
\text { @. } 850 \mathrm{~nm} \\
\end{array}$ \\
\hline Exguide $^{\mathrm{TM}}$ & $\begin{array}{l}\text { FOWG series from } \\
\text { Chemoptics Inc. }\end{array}$ & $\begin{array}{l}<0.1 \mathrm{~dB} / \mathrm{cm} \\
\text { (a) } 850 \mathrm{~nm}\end{array}$ & $\begin{array}{c}1.547 \\
\text { @. } 830 \mathrm{~nm} \\
\end{array}$ \\
\hline GuideLink $^{\mathrm{TM}}$ & Optical Crosslinks & $\begin{array}{c}\sim 0.1 \mathrm{~dB} / \mathrm{cm} \\
@ 850 \mathrm{~nm} \\
0.35 \mathrm{~dB} / \mathrm{cm} \\
\text { a } 1300 \mathrm{~nm}\end{array}$ & $\begin{array}{c}1.505 \\
@ 850 \mathrm{~nm}\end{array}$ \\
\hline OE-4140 UV & Dow Corning & $\begin{array}{c}0.04 \mathrm{~dB} / \mathrm{cm} \\
(a, 850 \mathrm{~nm}\end{array}$ & $\begin{array}{c}1.52 \\
\text { (a) } 850 \mathrm{~nm} \\
\end{array}$ \\
\hline Ormocore & $\begin{array}{l}\text { micro resist } \\
\text { technology } \mathrm{GmbH}\end{array}$ & $\begin{array}{c}0.1 \mathrm{~dB} / \mathrm{cm} \\
@ 633 \mathrm{~nm} \\
0.23 \mathrm{~dB} / \mathrm{cm} \\
@ 1310 \mathrm{~nm} \\
0.6 \mathrm{~dB} / \mathrm{cm} \\
@ 1550 \mathrm{~nm}\end{array}$ & $\begin{array}{c}1.553 \\
\text { (a) } 635 \mathrm{~nm}\end{array}$ \\
\hline Polyguide ${ }^{\mathrm{TM}}$ & DuPont & $\begin{array}{c}0.08 \mathrm{~dB} / \mathrm{cm} \\
@ 800 \mathrm{~nm} \\
0.35 \mathrm{~dB} / \mathrm{cm} \\
@ 1300 \mathrm{~nm}\end{array}$ & $1.485-1.51$ \\
\hline Truemode ${ }^{\mathrm{TM}}$ & Exxelis & $\begin{array}{l}0.04 \mathrm{~dB} / \mathrm{cm} \\
\text { (a) } 850 \mathrm{~nm}\end{array}$ & $\begin{array}{c}1.57 \\
@ 633 \mathrm{~nm} \\
\end{array}$ \\
\hline Ultradel 9120D & Amoco chemicals & $\begin{array}{c}0.34 \mathrm{~dB} / \mathrm{cm} \\
@ 850 \mathrm{~nm} \\
0.43 \mathrm{~dB} / \mathrm{cm} \\
@ 1300 \mathrm{~nm}\end{array}$ & $\begin{array}{c}1.547 \\
@ 850 \mathrm{~nm} \\
1.535 \\
@ 1550 \mathrm{~nm}\end{array}$ \\
\hline
\end{tabular}

Tab. 1. The list of the polymer materials for optical interconnections and photonics applications.

of polymers suitable for photonics applications is summarized in Tab. 1.

In this paper, the siloxane-based system commercially known as LightLink ${ }^{\mathrm{TM}}$ (developed by Rohm and Haas, and now commercial available from micro resist technology $\mathrm{GmbH}$ ) was used for realization of optical waveguides. This polymer has suitable properties (optical losses $\sim 0.05 \mathrm{~dB} \cdot \mathrm{cm}^{-1}$ at $850 \mathrm{~nm}, \sim 0.3 \mathrm{~dB} \cdot \mathrm{cm}^{-1}$ at $1310 \mathrm{~nm}$, $>1 \mathrm{~dB} \cdot \mathrm{cm}^{-1}$ at $1510 \mathrm{~nm}$ [17]) and its easy fabrication process compatible with technology already used for siliconbased devices makes it technologically feasible and cheaper. Here, for our experiments, we used flexible transparent paper Xerox 3R96525 (Xerox Corporation) and PLEXIGLAS ${ }^{\circledR}$ Film OF058 (Evonik Industries AG) as substrates.

\section{Siloxane Planar Waveguides}

LightLink $^{\mathrm{TM}}$ is a material from the silsesquioxanes family [18], [19]. These polymers are hybrid organic/inorganic materials that consist mainly of silicon and oxygen

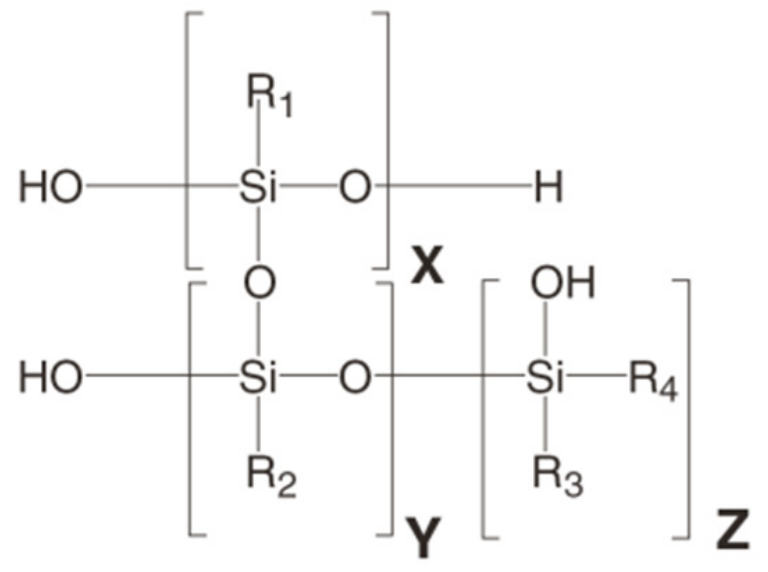

Fig. 1. Inorganic/organic polymer backbone of LightLink ${ }^{\mathrm{TM}}$ [18].

\begin{tabular}{|c|c|}
\hline \multicolumn{2}{|l|}{ Optical properties } \\
\hline LIGHTLINK $^{\text {TM }}$ XH-100145 Clad (Thermal) & $1.480 @ 850 \mathrm{~nm}^{*}$ \\
\hline $\begin{array}{l}\text { LIGHTLINK }{ }^{\text {TM }} \text { XP-07423A Clad (Photo- } \\
\text { thermal) }\end{array}$ & 1.480@850 nm* \\
\hline LIGHTLINK ${ }^{\mathrm{TM}}$ XP-6701A Core & $\begin{array}{l}1.512 @ 850 \mathrm{~nm}^{*} \\
0.05 \mathrm{~dB} / \mathrm{cm}^{* *} \\
0.30 \mathrm{~dB} / \mathrm{cm}^{* * *}\end{array}$ \\
\hline Xerox 3R96525 & $1.659 @ 850 \mathrm{~nm}^{*}$ \\
\hline 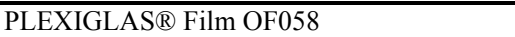 & $1.486 @ 850 \mathrm{~nm}^{*}$ \\
\hline \multicolumn{2}{|c|}{ "refractive index $(-),{ }^{* *}$ optical losses at $850 \mathrm{~nm},{ }^{* * * *}$ at $1310 \mathrm{~nm}$} \\
\hline \multicolumn{2}{|l|}{$\begin{array}{r}\text { Stability } \\
\end{array}$} \\
\hline $\begin{array}{l}\text { Sustained performance over } 100 \text { thermal c } \\
+70^{\circ} \mathrm{C}\end{array}$ & ween $-40^{\circ} \mathrm{C}$ and \\
\hline
\end{tabular}

Tab. 2. The properties of LightLink ${ }^{\mathrm{TM}}$ polymer [17].

and form a highly crosslinked network and might be a significant promise in the optical interconnection market due to their photoimaging, optical, hydrophobic and thermal stability properties. Silsesquioxane is known for its low moisture absorption and good thermal stability; its structure is illustrated in Fig. 1.

The formula lends itself to numerous configurations where R1, R2, R3 and R4 can be a combination of aliphatic and/or aromatic groups [18]. Depending upon the functional groups attached to the polymer backbone, various performance factors can be designed into the material, including dissolution rate, mechanical properties and optical loss. The siloxane nature of the LightLink ${ }^{\mathrm{TM}}$ waveguide system minimizes the intrinsic optical loss for $850 \mathrm{~nm}$ applications. The main properties of LightLink ${ }^{\mathrm{TM}}$ are shown in Tab. 2.

In our case planar optical waveguide is a step-index structure and consists of a high-index dielectric layer created from LIGHTLINK ${ }^{\mathrm{TM}}$ XP-6701A Core polymer $(65 \%$ solids weight in PGMEA) and is surrounded on the bottom side with lower index materials LIGHTLINK ${ }^{\mathrm{TM}} \mathrm{XH}-$ 100145 Clad deposited onto two different types of substrate. We used Xerox transparent paper (see Fig. 2a) or PLEXIGLAS $®$ Film OF058 substrate. Due to low value of refractive index of OF058 substrate it is not necessary to apply cladding layer (see Fig. 2b). Upper side environment is air in both cases (see Fig. 2). 

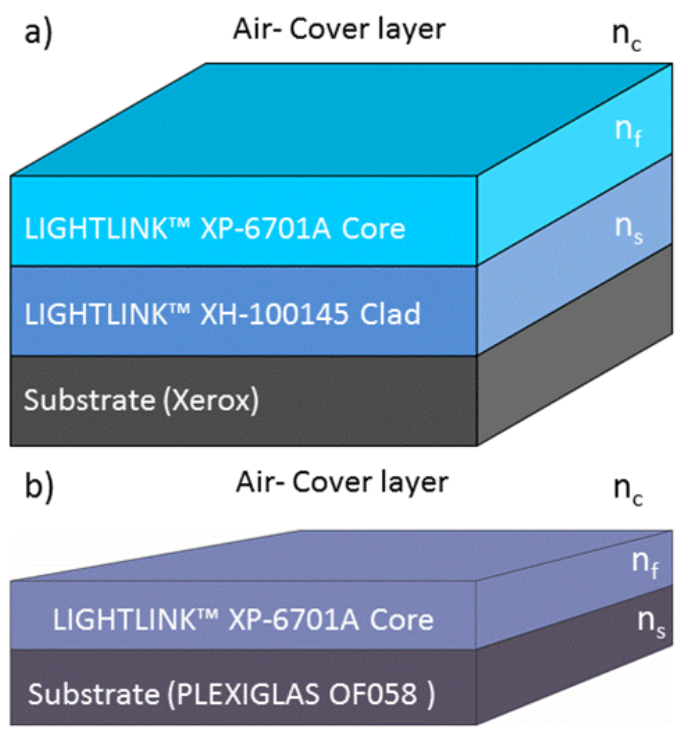

Fig. 2. Schema of an LIGHTLINK ${ }^{\mathrm{TM}}$ optical planar waveguide on a) Xerox substrate, b) PLEXIGLAS ${ }^{\circ}$ Film OF058 substrate.

\section{Experimental Procedures}

The experiments were performed on two types of the substrates. The first one was transparent paper Xerox 3R96525 (Xerox Corporation) and the second one was PLEXIGLAS ${ }^{\circledR}$ Film OF058 (Evonik Industries AG) foil. Fabrication process of the planar polymer flexible waveguides for Xerox substrate is illustrated in Fig. 3 step by step.

The first step was a standard cleaning procedure for substrate and followed by deposition LIGHTLINK ${ }^{\text {TM }}$ Clad using spin coating (Fig. 3a). The cladding layer was hardened on hot plate at $90^{\circ} \mathrm{C}$ for $2 \mathrm{~min}$ (Fig. 3b). Then LIGHTLINK $^{\mathrm{TM}}$ Core was deposited on the clad layer by spin coating (Fig. 3c) and after that soft bake process was applied at $95^{\circ} \mathrm{C}$ for $2 \mathrm{~min}$ on the hotplate (Fig. 3d). Next,

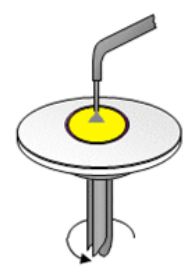

a)

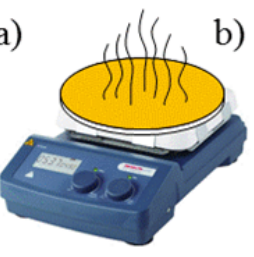

d)
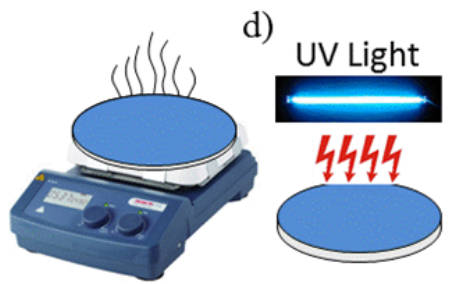

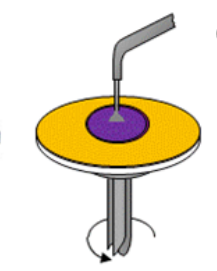

c)

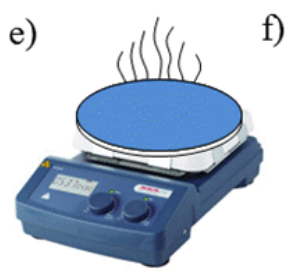

Fig. 3. Fabrication process for LIGHTLINK ${ }^{\mathrm{TM}}$ planar optical waveguides, a) deposition of LIGHTLINK ${ }^{\mathrm{TM}}$ clad layer, b) clad soft bake, c) deposition of LIGHTLINKTM $^{\mathrm{TM}}$ core waveguide layer, d) soft bake process, e) UV curing process, f) post exposure bake. applying of UV curing process (Fig. 3e) occurred and, finally, post exposure bake was done at $145^{\circ} \mathrm{C}$ for $60 \mathrm{~min}$ on the hotplate (Fig. 3f). Similar processes except the step a) and b) were applied for fabrication of LIGHTLINK ${ }^{\mathrm{TM}}$ waveguides onto PLEXIGLAS ${ }^{\circledR}$ Film OF058 substrates.

\section{Measurements and Results}

The thicknesses of the fabricated layers (cladding/ core) were measured by profile-meters Talystep Hommel Tester 1000. The experimentally found thicknesses of the waveguide layers were from 10 to $50 \mu \mathrm{m}$ depending on deposition condition (mainly depending on the rate of spinning of the spin coater).

Transmission spectra of the used LIGHTLINKTM Core, LIGHTLINK ${ }^{\mathrm{TM}}$ Clad, Xerox and PLEXIGLAS ${ }^{\circledR}$ Film OF058 substrate were collected by UV-VIS-NIR Spectrometer (UV-3600 Shimadzu) in the spectral range from 400 to $1600 \mathrm{~nm}$ and are given in Fig. 4. Obviously the waveguide layer is transparent within the whole range of the measured wavelengths and therefore LIGHTLINK ${ }^{\mathrm{TM}}$ Core polymer has suitable properties for optical waveguides.

Waveguiding properties of the planar waveguides were measured by prism coupling technique using Metricon 2010 prism-coupler system [20] at five wavelengths $473,632.8,964,1311$ and $1552 \mathrm{~nm}$. Refractive index of the planar waveguide can be determined by measuring the critical angle of the incidence at the interface between the prism and the material, which is in contact with the coupling prism. The measured sample is brought into contact with the base of the couple prisms by means of a pneumatically-operated coupling head leaving narrow air gap between the waveguide film and the prism. Laser beam strikes the base of the prism and is totally reflected at the prism base onto a photodetector at certain discrete values of the incident angle $\Theta$ called mode angles. For more details of these measurement see [14], [21].

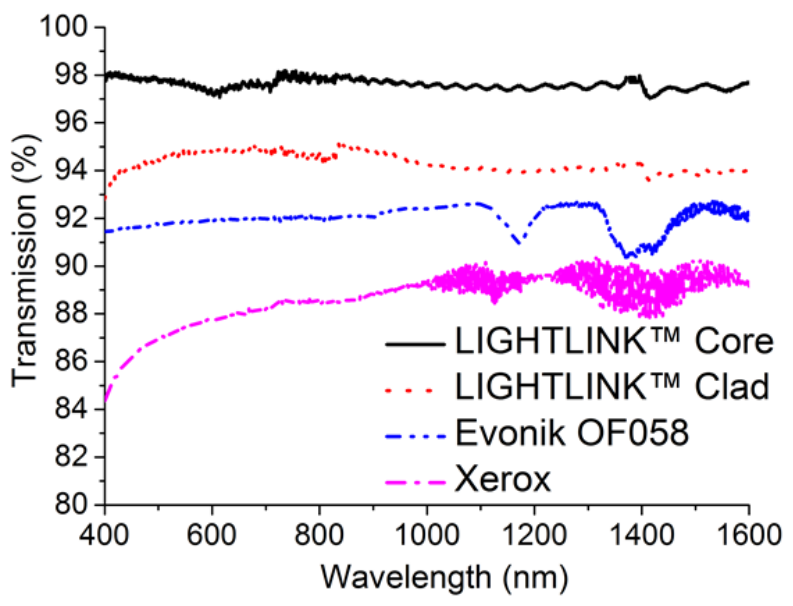

Fig. 4. Transmission spectra of the applied LIGHTLINK ${ }^{\mathrm{TM}}$ XP-6701A Core, LIGHTLINK TM XH-100145 Clad polymer, Xerox and PLEXIGLAS ${ }^{8}$ Film OF058 substrate. 

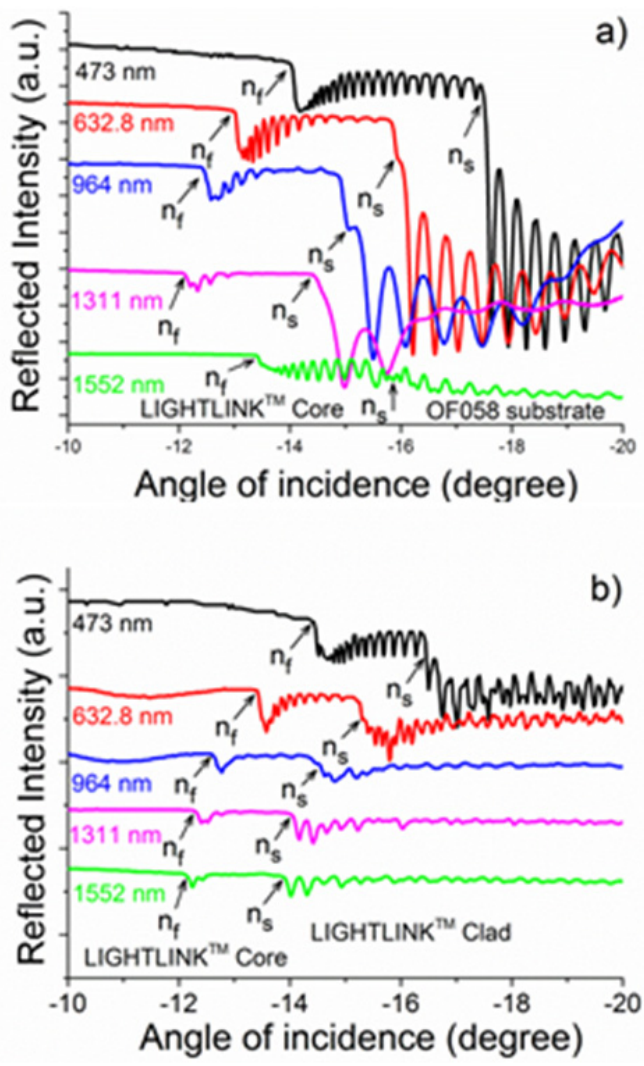

Fig. 5. Mode pattern (TE modes) of LIGHTLINK ${ }^{\mathrm{TM}}$ XP-6701A planar waveguides deposited onto a) PLEXIGLAS $®$ Film OF058 substrate, b) with LIGHTLINK ${ }^{\mathrm{TM}}$ XH-100145 Clad on Xerox 3R96525 paper.

The result in a form of mode spectra for LIGHTLINK $^{\mathrm{TM}}$ XP-6701A Core polymer deposited onto PLEXIGLAS ${ }^{\circledR}$ Film OF058 substrate is given in Fig. 5a and LIGHTLINK ${ }^{\mathrm{TM}}$ XP-6701A Core planar waveguides with LIGHTLINK ${ }^{\mathrm{TM}} \mathrm{XH}-100145$ Cladding deposited onto Xerox paper substrate is shown in Fig. 5b. The arrow with label $\mathrm{n}_{\mathrm{f}}$ indicates angel of incidents for refractive index of waveguide layer and label $n_{s}$ indicates angel of incidents for refractive index of cladding layer respectively.

The first arrows indicate the edge between the cover layer (air) and LIGHTLINK ${ }^{\mathrm{TM}}$ Core layer. Abstracting the edge of incidence we get refractive indices of the waveguiding layer $n_{\mathrm{f}}$. The second arrows indicate the edge between LIGHTLINK ${ }^{\mathrm{TM}}$ Core layer and LIGHTLINK ${ }^{\mathrm{TM}}$ Clad layer and here abstracting the edge of incidence we get refractive indices of LIGHTLINK ${ }^{\mathrm{TM}}$ Clad layer $n_{\mathrm{s}}$. Refractive index of the substrate (paper or foil) cannot be determined as the cladding is too thick.

Refractive indices of the LIGHTLINK ${ }^{\mathrm{TM}}$ Clad and LIGHTLINK ${ }^{\text {TM }}$ Core waveguides determined for the mode patterns are in Fig. 6 compared with the values given by the producer (red line and the black point in the lower part of the figure). The agreement of the data of our waveguiding layer (blue line) with the professional one (red line) is obvious. Refractive indices of our cladding are higher than those given by the producer, and it is so because we used different curing temperatures.

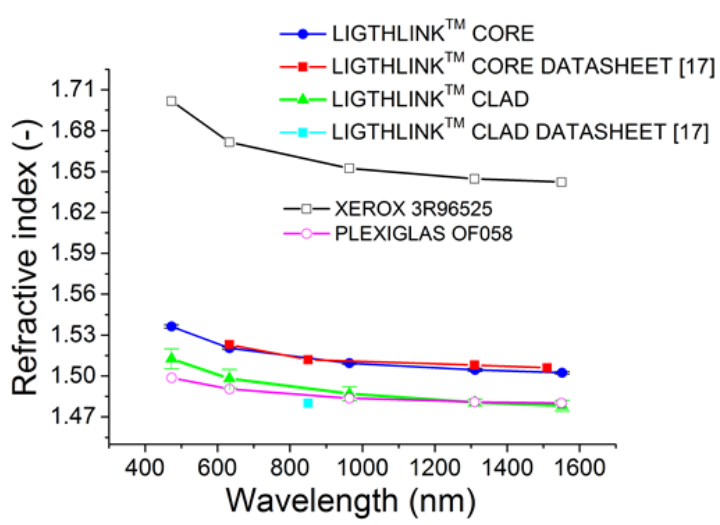

Fig. 6. Evaluation of the refractive indices from mode pattern measurement obtained from using Metricon 2010 prism-coupler system (TE modes) and compared with datasheet [17]

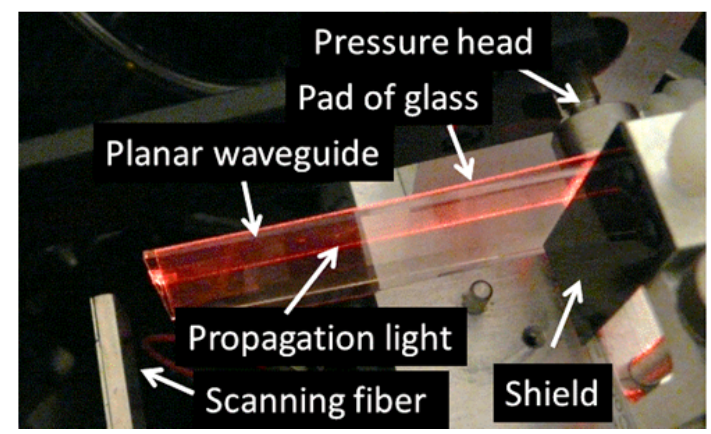

Fig. 7. Coupling of the optical signal $(632.8 \mathrm{~nm})$ into flexible polymer waveguides for optical loss measurements.

Figure 7 shows an image of planar waveguides supporting optical light at $632.8 \mathrm{~nm}$. This figure shows that our waveguide had good optical properties. The flexible polymer sample must be fixed to a pad of a glass; otherwise the planar waveguides might bend, which would make achieving of quality optical contact difficult and thus making worse the coupling of the laser beam into the waveguide.

Optical losses of the planar waveguides were measured by fiber scanning method [22]. The assumption is that at every point on the propagating streak the light scattered from the surface and picked up by the fiber is proportional to the light which remains within the guide. The best exponential fit to the resulting intensity vs distance curve yields the loss in $\mathrm{dB} / \mathrm{cm}$. The results of the optical loss measurements are demonstrated in Fig. 8. Figure 8 a shows the results for the sample LIGHTLINK ${ }^{\mathrm{TM}}$ Core fabricated on PLEXIGLAS ${ }^{\circledR}$ Film OF058 substrate and Figure 8b shows the results for the sample LIGHTLINK ${ }^{\mathrm{TM}}$ Core fabricated on Xerox 3R96525 substrate.

Our optical planar waveguides had optical losses lower than $0.5 \mathrm{~dB} \cdot \mathrm{cm}^{-1}$ with the best sample having optical losses as low as $0.25 \mathrm{~dB} \cdot \mathrm{cm}^{-1}$. Just for possible interest: the obtained values of optical losses are comparable with presented data in [23] $0.6 \mathrm{~dB} / \mathrm{cm}(1550 \mathrm{~nm}),<0.1(850 \mathrm{~nm})$ and [24] $0.34 \mathrm{~dB} / \mathrm{cm}(1310 \mathrm{~nm})$ or $0.05 \mathrm{~dB} / \mathrm{cm} 850 \mathrm{~nm}$ [19], but it must be kept in mind the above mentioned data were given for ridge waveguides. 


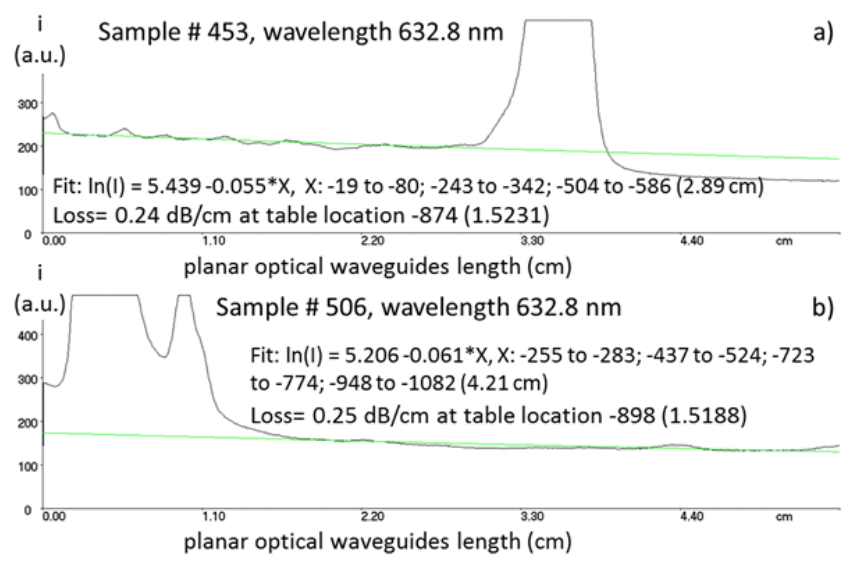

Fig. 8. Optical losses of the LIGHTLINK ${ }^{\mathrm{TM}}$ XP-6701A planar waveguides deposited onto a) OF058, b) Xerox.

\section{Conclusion}

We report about properties of siloxane (LightLink ${ }^{\mathrm{TM}}$ ) optical planar waveguides deposited onto Xerox 3R96525 transparent paper and PLEXIGLAS ${ }^{\circledR}$ Film OF058 foil. Planar waveguides were deposited by spin coating after that UV curing was applied for hardening of the deposited waveguide layers. Optical waveguiding properties of our planar waveguides samples were characterized by Metricon 2010 prism-coupler system for five wavelengths (473, $632.8,964,1311$ and $1552 \mathrm{~nm}$ ) and we proved that our samples had waveguiding properties at all the measured wavelengths. Optical losses were measured by collecting the scattered light using fiber scanning along the waveguide read by the Si photodetector at $632.8 \mathrm{~nm}$. The samples had optical losses lower than $0.5 \mathrm{~dB} \cdot \mathrm{cm}^{-1}$ and our best sample has optical losses around $0.25 \mathrm{~dB} \cdot \mathrm{cm}^{-1}$.

The main advantage of our samples is that they are deposited on flexible substrates what makes them suitable for advanced sophisticated interconnection devices. Next we are going to design and construct multimode flexible ridge waveguides based on the same principle.

\section{Acknowledgments}

The authors thank Evonik Industries AG for providing PLEXIGLAS ${ }^{\circledR} \quad$ Film OF058 foils. This work was supported by the Epsilon Programme of the Technology Agency of the Czech Republic, project no. TH01020276, and by the CTU grant no. SGS14/195/OHK3/3T/13.

\section{References}

[1] BAMIEDAKIS., N., CHEN, J., PENTY, R.V., et al. Bandwidth studies on multimode polymer waveguides for $\geq 25 \mathrm{~Gb} / \mathrm{s}$ optical interconnects. IEEE Photonics Technology Letters, 2014, vol. 26, no. 20, p. 2004-2007. DOI: 10.1109/LPT.2014.2342881

[2] UHLIG, S., ROBERTSSON, M. Limitations to and solutions for optical loss in optical backplanes. Journal of Lightwave
Technology, 2006, vol. 24, no. 4, p. 1710-1724. DOI: 10.1109/JLT.2006.870978

[3] YOShITAKE, N., TERAKAWA, Y., HOSOKAWA, H. Polymer optical waveguide devices for FTTH. In Proceedings of the OptoElectronics and Communications Conference. Sydney (Australia). 2008, p. 305-306. ISBN:978-0-85825-863-1

[4] KOBAYASHI, J., YAGI, S., HATAKEYAMA, Y., et al. Low loss polymer optical waveguide replicated from flexible film stamp made of polymeric material. Japanese Journal of Applied Physics, 2013, vol. 52, no. 7, UNSP 072501. DOI: 10.7567/JJAP.52.072501

[5] PAVESI, L., LOCKWOOD, D.J. Silicon Photonics. Berlin Heidelberg New York: Springer-Verlag, 2004. ISBN: 3-540-21022-9

[6] LOCKWOOD, D. J. Silicon Photonics II. Heidelberg Dordrecht London New York: Springer, 2011. ISBN: 978-3-642-10506-7

[7] BOOTH, B. L. Low-loss channel wave-guides in polymers. Journal of Lightwave Technology, 1989, vol. 7, no. 10, p. 1445-1453. DOI: $10.1109 / 50.39079$

[8] WONG, W.H., LIU, K.K., CHAN, K.S., et al. Polymer devices for photonics applications. Journal of Crystal Growth, 2006, vol. 288, no. 1, p. 100-104. DOI: 10.1016/j.jcrysgro.2005.12.017

[9] LYUTAKOV, O., TUMA, J., PRAJZLER, V., et al. Preparation of rib channel waveguides on polymer in electric field. Thin Solid Films, 2010, vol. 519, no. 4, p. 1452-1457. DOI: 10.1016/j.tsf.2010.08.019

[10] MA, H., JEN, A.K.Y., DALTON, L. R. Polymer based optical waveguides: Materials, processing and devices. Advanced Materials, 2002, vol. 14, no. 19, p. 1339-1365. DOI: $10.1002 / 1521-4095$

[11] ELDADA, L. Optical communication components. Review of Scientific Instruments, 2004, vol. 75, no. 3, p. 575-593. DOI: 10.1063/1.1647701

[12] PRAJZLER, V., KLAPUCH, J., LYUTAKOV, O., et al. Design. fabrication and properties of rib poly (methylmethacrylimide) optical waveguides. Radioengineering, 2011, vol. 20, no. 2, p. 479-485. ISSN: 1210-2512.

[13] PRAJZLER, V., NEKVINDOVÁ, P., HYPŠ, P., et al. Properties of the optical planar polymer waveguides deposited on printed circuit boards. Radioengineering, 2015, vol. 24, no. 2, p. 442-448. DOI: $10.13164 /$ re.2015.0442

[14] PRAJZLER, V., NEKVINDOVÁ, P., HYPŠ, P., et al. Flexible polymer planar optical waveguides. Radioengineering, 2014, vol. 23, no. 3, p. 776-782. ISSN: 1210-2512.

[15] SWATOWSKI, B.W., AMB, C.M., BREED, S.K., et al. Flexible, stable, and easily processable optical silicones for low loss polymer waveguides. In Proceedings of SPIE Conference on Organic Photonic Materials and Devices XV. San Francisco (USA), 2013, vol. 8622, Article number: 862205. DOI: $10.1117 / 12.2007419$

[16] BOSMAN, E., Van STEENBERGE, G., HENDRICKX, N., et al. Multimode optical interconnections embedded in flexible electronics. In Proceedings of the 16th European Microelectronics and Packaging Conference EMPC. Oulu (Finland), 2007, p. 155-160. ISBN: 978-952-99751-1-2.

[17] LightLink ${ }^{\mathrm{TM}}$ data sheets: Micro Resist Technology GmbH. Available at: http://www.microresist.de

[18] MOYNIHAN, M., SICARD, B., HO, T., et al. Progress towards board-level optical interconnect technology. Proceedings of SPIE, 2005, vol. 5731, p. 50-62. DOI: 10.1117/12.594675

[19] ANZURES, E., DANGEL, R., BEYELER, R., et al. Flexible optical interconnects based on silicon-containing polymers. Proceedings of SPIE, 2009, vol. 7221, Article Number 72210I. ISBN: 978-0-8194-7467-4. DOI: 10.1117/12.808396 
[20] METRICON CORPORATION: www.metricon.com

[21] PRAJZLER, V., NEKVINDOVÁ, P., HYPŠ, P., et al. Optical properties of polymer planar waveguides deposited on flexible foils. Journal of Optoelectronics and Advanced Materials, 2015 vol. 17 , no. 11-12, p.1597-1602. ISSN: 1454-4164.

[22] NOURSHARGH, N., STARR, E. M., FOX, N. I., et al. Simple technique for measuring attenuation of integrated optical waveguides. Electronics Letters, 1985, vol. 21, no. 18, p. 818-820. DOI: $10.1049 / \mathrm{el}: 19850577$

[23] MOYNIHAN, M., ALLEN, C., HO, T., et al. Hybrid inorganicorganic aqueous base compatible waveguide materials for optical interconnect applications. Proceedings of SPIE, 2003, vol. 5212, p. 50-60. DOI: $10.1117 / 12.508142$

[24] ELMOGI, A., BOSMAN, E., MISSINNE, J., et al. Comparison of epoxy- and siloxane-based single-mode optical waveguides defined by direct-write lithography. Optical Materials, 2016, vol. 52, p. 26-31. DOI: 10.1016/j.optmat.2015.12.009

\section{About the Authors ...}

Václav PRAJZLER was born in 1976 in Prague, Czech Republic. In 2001 he graduated from the Faculty of Electrical Engineering, Czech Technical University in Prague, Dept. of Microelectronics. In 2007 he obtained the PhD degree from the same university. Since 2014 he has been an Associate Professor of Electronics with the Department of Microelectronic, Czech Technical University in Prague.
His current research is focused on design, fabrication and investigation of properties of photonics structures.

Petr HYPŠ was born in 1989 in Pelhrimov, Czech Republic. He obtained his MSc degree from the Department of Measurement, Faculty of Electrical Engineering, Czech Technical University in Prague in 2015 and his thesis dealt with design, fabrications and measurements of properties of optical polymer planar waveguides.

Radek MAŠTERA was born in 1989. His bachelor degree was reached at the Dept. of Microelectronics, Faculty of Electrical Engineering, Czech Technical University in Prague in 2012. He obtained his MSc degree from the Dept. of Measurement, Faculty of Electrical Engineering, Czech Technical University in Prague in 2015 and his thesis dealt with design, fabrications and measurements of properties of optical polymer planar selective wavelength structure for $1 \mathrm{~mm}$ diameter core Plastic Optical Fiber.

Pavla NEKVINDOVÁ was born in 1972 in Kolín, Czech Republic. She graduated from the Institute of Chemical Technology, Prague (ICTP) in 1999. Now she is an Assistant Professor at the ICTP giving lectures on general and inorganic chemistry. She has worked there continuously in materials chemistry research. She has a long-term experience with fabrication and characterization of optical waveguiding structures in single-crystalline and glass materials. 